\title{
Selection for abdominal bristle number in Drosophila subobscura, a highly polymorphic species for gene arrangements
}

\author{
Maria-José MARTINEZ-SEBASTIAN and J.L. MENSUA \\ Departamento de Genética, Facultad de Ciencias Biológicas, \\ Avd. Dr. Moliner, 50, Burjasot (Valencia), Spain
}

\begin{abstract}
Summary
Two replicate selection lines for abdominal bristle number in both high and low directions and 2 control lines were established from a laboratory population of Drosophila subobscura and were run for 23-24 generations. The sum of the bristles on the 4th and 5th abdominal sternites was the criterion of selection and the intensity of selection used was 20 p. 100.

Response to selection was very similar to the response obtained by other authors in Drosophila melanogaster. This indicates that the behaviour of the genotype responsible for the abdominal bristle number may be similar in the 2 species, in spite of the fact that Drosophila subobscura is very rich in chromosomal polymorphisms and Drosophila melanogaster is very poor.
\end{abstract}

Key words : Artificial selection, neutral trait, Drosophila subobscura.

\section{Résumé}

Sélection pour le nombre de soies abdominales chez Drosophila subobscura, espèce très polymorphe pour les arrangements géniques

On a établi 2 lignées de sélection (haute et basse) pour le nombre de soies abdominales ainsi que 2 lignées témoins à partir d'une population de laboratoire de Drosophila subobscura. On a conduit la sélection pendant 23-24 générations. Le caractère sélectionné était le nombre de soies des $4^{\mathrm{e}}$ et $5^{\mathrm{e}}$ sternites de l'abdomen et l'intensité de sélection était de 20 p. 100.

La réponse à la sélection a été semblable à celle obtenue par d'autres auteurs chez Drosophila melanogaster. Cette concordance indique que la nature du génotype responsable du nombre de soies abdominales peut être similaire dans les 2 espèces, bien que Drosophila subobscura montre un polymorphisme chromosomique beaucoup plus riche que Drosophila melanogaster.

Mots clés : Sélection artificielle, caractère neutre, Drosophila subobscura. 


\section{Introduction}

An important characteristic of Drosophila subobscura is that inversion polymorphisms are found on all of its major chromosomes. These polymorphisms have not only been studied intensively from a structural and a evolutionary point of view, but also relative to other characters such as enzymatic polymorphisms and morphological traits (see an update review by Krimbas \& Loukas, 1980).

PrevostI (1967), while artificially selecting for an adaptative trait, wing length, in Drosophila subobscura, found a stronger response than that obtained in Drosophila melanogaster by other workers using the same selection criteria. One of the explanations given for this was that the numerous inversions in $D$. subobscura facilitated selection response.

These results suggested that it would be interesting to study the relationships between neutral traits and chromosomal polymorphisms, and specifically to determine whether the presence of inversions facilitates selection response in a neutral trait. For this reason, an artificial selection experiment for abdominal bristle number in $D$. subobscura was initiated. Abdominal bristle number is classically considered to be a neutral character (Clayton et al., 1957 ; LATTER \& RoberTson, 1962) and has been used in a large number of artificial selection experiments in D. melanogaster (MATHER \& Harrison, 1949 ; Rasmuson, 1955 ; Clayton et al., 1957 ; Sheldon, 1963 ; FranKHAM et al., 1968 ; Yoo, 1980). The response to selection for this neutral trait obtained in $D$. subobscura, a species with high level of inversion polymorphisms, was then compared to the responses reported in $D$. melanogaster, a species with a low level of inversion polymorphisms.

\section{Material and methods}

A sample of 32 females of a wild population of D. subobscura, from Ribarroja (Valencia, Spain), was used to start the population used in this experiment. The population was maintained in the laboratory for 5 months before the experiment began.

Before selection began, the heritability of abdominal bristle number was estimated from offspring-parent regression analysis. Egg samples were obtained from the laboratory population and placed in food bottles under conditions of optimal density. Samples of males and females were taken from the bottles and each male was allowed to mate in a separate bottle with a virgin female. When the progeny emerged, 4 males and 4 females were scored for each of 150 couples producing offspring.

From the laboratory population, 2 replicate selection lines for abdominal bristle number in both high ( $\mathrm{H} 1$ and $\mathrm{H} 2)$ and low (L1 and L2) directions and 2 control lines (C1 and $\mathrm{C} 2$ ) were run 23-24 generations. The sum of the bristles on the 4th and 5th sternites was the criterion used in selection and the intensity of selection was 20 p. 100 . Twenty males and 20 females from each of 6 bottles in each of the 2 high and low lines were scored each generation. The most extreme 4 males and 4 females from each bottle were selected. Therefore in each line 240 individuals were scored and 48 individuals were selected for breeding each generation. In each of the control lines 20 males and 
20 females were also selected and scored from each of the 6 bottles. Again 4 males and 4 females were selected for breeding. In these lines, however, the selection was done randomly.

The 48 flies selected from each of the 6 lines in each generation were left for 24 hours on medium (RoBERTSON, 1960) and afterwards the eggs were collected. In all cases 100 eggs were placed in each bottle $(125 \mathrm{ml})$ to prevent overcrowding.

All flies developed at $19{ }^{\circ} \mathrm{C}$ and standard corn meal medium supplemented with live yeast was used.

\section{Results}

The means and coefficients of variation of the character distributions in the females from the wild and laboratory populations are given in table 1 . The mean is higher and the coefficient of variability lower for the laboratory population, which is as expected since a natural environment is less homogeneous than one in the laboratory.

TABLE 1

Mean $(\bar{X})$ and coefficient of variation $(C . V$.$) with standard errors$ of the natural and laboratory populations.

\begin{tabular}{l|c|c|c|c}
\hline \hline & & $\mathrm{N}^{\circ}$ scored & $\overline{\mathrm{X}}$ & C.V. \\
\cline { 2 - 5 } Natural population (females) $\ldots \ldots \ldots \ldots$ & 32 & $31.88 \pm 0.77$ & $13.73 \pm 1.75$ \\
Laboratory population (females) $\ldots \ldots \ldots \ldots$ & 480 & $34.76 \pm 0.16$ & $10.27 \pm 0.34$ \\
Laboratory population (males) $\ldots \ldots \ldots \ldots$ & 480 & $35.30 \pm 0.18$ & $10.90 \pm 0.36$ \\
\hline \hline
\end{tabular}

The heritability estimate of the laboratory population and its standard error were $0.40 \pm 0.05$. This value was sufficiently large to ensure a good response in a mass selection exercise.

Figure 1 shows the results of 23-24 generations of selection in the high, low and control lines. The total increase in the $\mathrm{H} 1$ and $\mathrm{H} 2$ high selection lines was 40 and 37 respectively. In both lines, the response was greater in early generations as compared to the later generations. The rate of response in the 2 replicate lines was very similar.

The behaviour of low selection lines was very similar to that displayed by the high selection lines, but the response was much slower after the first few generations. The total response resulted in a decrease of 23 and 21 bristles in the L1 and L2 lines respectively. The response was slower in these lines, particularly in the later generations, because some of the flies had already attained the lower limit of zero bristles. Also in later generations individuals showing gross defects in the sclerotization of the abdomen appeared, which disguised the true effect of selection (RASMUSON, 1955; Clayton et al., 1957).

In both the $\mathrm{C} 1$ and $\mathrm{C} 2$ control lines the mean bristle number tended to remain somewhat constant but with a slight tendency to increase. 


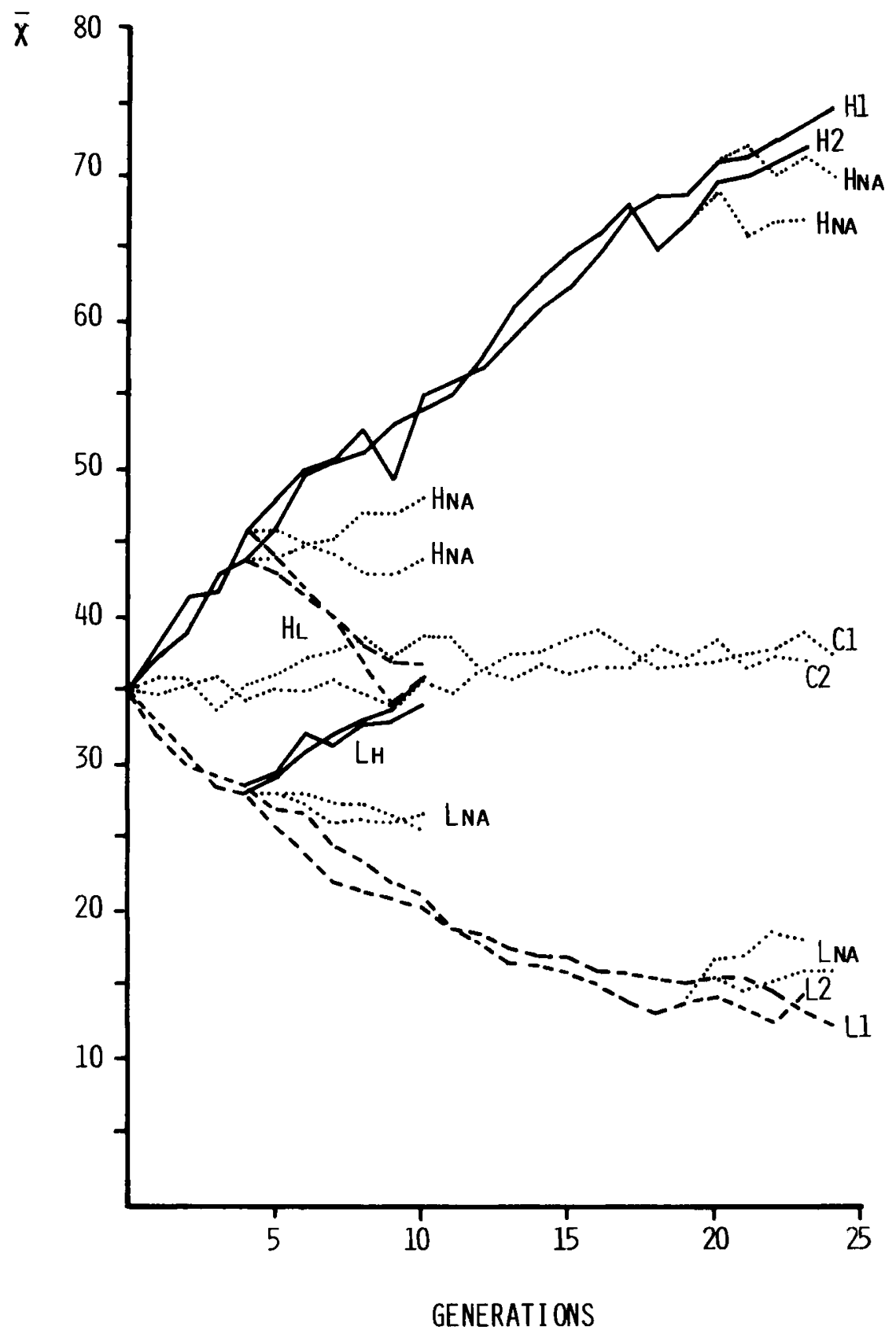

Fig. 1

Mean abdominal bristle number in high ( $\mathrm{H1}$ and H2), low (L1 and L2), control lines (C1 and C2), reverse selection ( $\mathrm{Hl}$ and $\mathrm{Lh}$ ) and natural selection lines (Hna and Lna). 
The mean of 35 bristles in the laboratory population at the start had changed to a mean of 37 bristles by the end of the experiment.

Overall the response to the selection was asymmetrical, being much greater when sèlection was for high bristle number. This asymmetry, which appears in the first generations, seems to be due to the effect of scale because the realized heritability was the same in the high and low selection lines, at least during the early generations. In the L2 line heritability dropped to zero in the later generations.

Sublines were taken from all high and low selection lines at the 4th generation and submitted to reverse selection for 6 generations. These sublines were developed under the same conditions as selection lines. In all reverse selection lines (fig. 1) the mean of the character increased or decreased and reached the mean value of the control lines in 5 generations. These results indicate that all selected lines retained a high level of variability in spite the changes that occurred in the means (FrankHam et al., 1968).

At the 4th and 20th generations of selection, natural selection sublines were developed from each high and low selection line (fig. 1). In all but one of these natural selection lines, the mean remained constant and did not show any tendency to revert to initial values. The second time natural selection lines were developed, the line from L2 showed a different behaviour. As can be seen in figure 1, the bristle number of that line increased and its coefficient of variation decreased markedly (from 38 to 12).

In all directional selection lines the coefficient of variation (fig. 2) remained more or less constant until the 9th generation. After that the high and low selection lines began to show different behaviours. In both the control and high selection lines, the coefficient of variation did not show significant changes or decreased slightly. In the low selection lines, the coefficient of variation increased significantly, particularly in the L2 line.

In order to know some characteristics of the genotypes selected, reciprocal crosses between selection lines were made when the selection process had been completed (tabl. 2). In each cross 60 males and 60 females were mated and 120 individuals of each sex of the F1 and F2 were scored.

TABLE 2

Mean values with standard errors of the crosses between selected lines (H1 and $\mathrm{H} 2$ high selection, LI and L2 low selection).

\begin{tabular}{|c|c|c|c|c|}
\hline & & \multicolumn{3}{|c|}{ Generation } \\
\hline & & $\mathbf{P}$ & $\mathrm{F} 1$ & F2 \\
\hline Q $\mathbf{L 1} \times \mathrm{O}^{n} \mathbf{H} 1$ & $\begin{array}{c}q \\
+ \\
\text { ơ } \\
\text { mean }\end{array}$ & $\begin{array}{l}11.78 \pm 0.23 \\
74.55 \pm 0.62 \\
43.17 \pm 2.90\end{array}$ & $\begin{array}{l}34.13 \pm 0.30 \\
28.70 \pm 0.29 \\
31.42 \pm 0.27\end{array}$ & $\begin{array}{l}30.07 \pm 0.67 \\
34.63 \pm 0.87 \\
32.35 \pm 0.57\end{array}$ \\
\hline$q \mathrm{H} 1 \times \sigma^{\prime} \mathrm{L} 1$. & $\begin{array}{c}q \\
O^{\prime \prime} \\
\text { mean }\end{array}$ & $\begin{array}{l}74.48 \pm 0.66 \\
13.47 \pm 0.33 \\
43.98 \pm 2.82\end{array}$ & $\begin{array}{l}33.87 \pm 0.29 \\
41.41 \pm 0.28 \\
37.64 \pm 0.32\end{array}$ & $\begin{array}{l}39.14 \pm 0.81 \\
35.93 \pm 0.71 \\
37.54 \pm 0.55\end{array}$ \\
\hline ㄴ $\mathbf{L} 2 \times \mathrm{O}^{\top} \mathbf{H} 2$ & $\begin{array}{c}q \\
\stackrel{7}{\sigma} \\
\text { mean }\end{array}$ & $\begin{array}{l}12.25 \pm 0.71 \\
73.17 \pm 0.75 \\
42.71 \pm 2.84\end{array}$ & $\begin{array}{l}30.62 \pm 0.67 \\
30.73 \pm 0.50 \\
30.68 \pm 0.42\end{array}$ & $\begin{array}{l}30.86 \pm 0.62 \\
35.71 \pm 0.71 \\
33.28 \pm 0.50\end{array}$ \\
\hline$q \mathrm{H} 2 \times \sigma^{\top} \mathrm{L} 2$ & $\begin{array}{c}q \\
\sigma^{\prime \prime} \\
\text { mean }\end{array}$ & $\begin{array}{l}72.40 \pm 0.64 \\
15.77 \pm 0.53 \\
44.08 \pm 2.63\end{array}$ & $\begin{array}{l}38.69 \pm 0.25 \\
45.13 \pm 0.35 \\
41.91 \pm 0.30\end{array}$ & $\begin{array}{l}40.28 \pm 0.65 \\
38.02 \pm 0.73 \\
39.15 \pm 0.49\end{array}$ \\
\hline
\end{tabular}




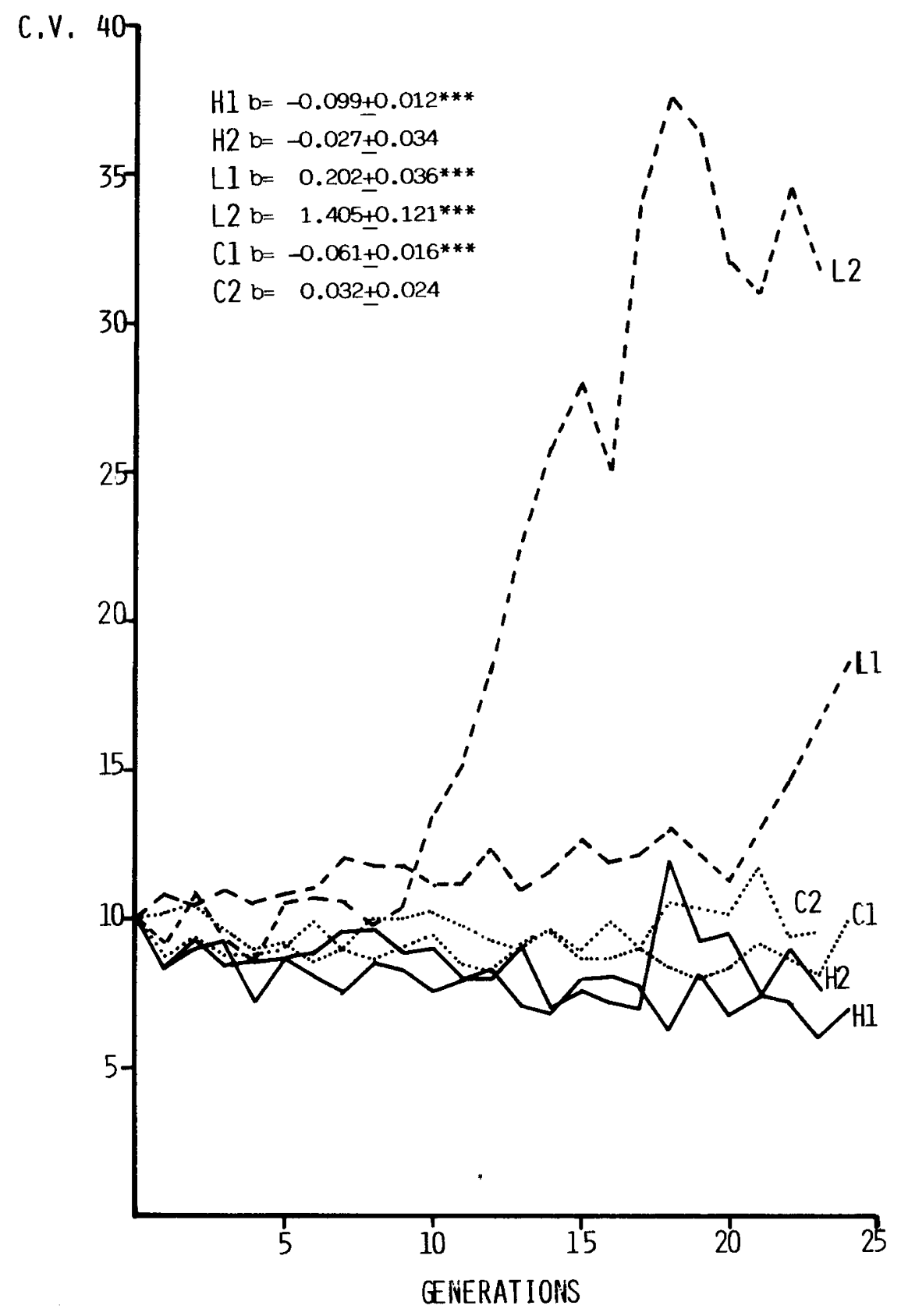

Fig. 2

Coefficient of variation of the high ( $\mathrm{Hl}$ and $\mathrm{H2}$ ), low ( $\mathrm{L1}$ and $\mathrm{L2}$ ) and control lines (C1 and $\mathrm{C2}$ ). In the top of the figure are slopes of regressions (b) between coefficients of variation and generations with standard errors for each line. ${ }^{* * *}$ indicates $b$ statistically different from zero at the level $P=0.001$. 
Differences between males and females of the F1 indicate that there are factors on the $X$ chromosome. In addition mean values of males and females of the $F 2$ of each cross increased or decreased in respect to the $\mathrm{F} 1$ values as was expected.

As can be seen in table 2, the mean value of the $\mathrm{F} 1$ from crosses between selected lines was usually smaller than the average of the parents. The explanation for this may be that the genes responsible for low bristle number are partially dominant over the genes for high bristle number. Such an effect has been found by FrankHam (1970). Clayton et al. (1957), Kidwell \& Kidwell (1966) and Rathie \& Nicholas (1980), however, found complete additivity for the same character.

The sex-dimorphism ratio oscillated between 1 and 1.02 in the laboratory population. These values indicated that there is no sex-dimorphism with respect to abdominal bristle number in D. subobscura, in contrast to other species (Yoo et al., 1981). The response pattern was very similar between sexes within a line. ANCova analysis shows significant differences between sexes only in the $L 2$ line $(F=4.3, P=0.05)$.

Both selected and control lines show a considerable oscillation in viability, but the regression of viability on generation number is significant only in a few cases. These regressions are negative in all lines except $\mathrm{C} 1$, which suggests that the process of selection leads to a decrease in viability, as is typical in artificial selection experiments.

\section{Discussion}

Prevosti (1967), making artificial selection for wing length in D. subobscura, found a response stronger than the response obtained by other workers using the same selection criteria in $D$. melanogaster. One of the explanations given for this was that there were numerous inversions present in the populations he submitted to selection. During selection, the blocks of genes included in inversions apparently can behave as "supergenes" in controlling differences in wing length. So, at least in the early generations, selection is concerned with only a few units, each with a large effect. $D$. melanogaster does not have numerous inversions on the chromosomes, consequently selection acts on many more individual units (single genes) associated with polygenic variation. Thus the long-term selection effect is greater but the short-term selection response is slower (Prevosti, 1967).

In the present experiment, using a population of $D$. subobscura highly polymorphic for numerous inversions (MARTinez-Sebastian \& DE Frutos, 1983), a response to shortterm selection greater than the response obtained in $D$. melanogaster, and a lesser response to long-term selection, would be expected. Yet by comparing the results with previous studies on D. melanogaster (Clayton et al., 1957 ; Clayton \& Robertson, 1957 ; Sheldon, 1963 ; Frankham et al., 1968 ; etc.) it can be seen that the response is very similar in the 2 species. Clayton et al. (1957), using the same intensity of selection (20 p. 100), obtained a response of 2.6 bristles per generation in high selection lines and 1.5 bristles in low selection lines, during the first five generations. In the present experiment a very similar response was observed ( 2.5 and 1.6 respectively) in the first five generations. Considering the entire 24 generations of selection, the response in the 2 species was remarkably similar. 
The response of natural selection sublines indicates that the forces regulating the maintenance of bristle number are not very strong and that the factors determining bristle number are really neutral for natural selection (FALCONER, 1981) in much the same way as in Drosophila melanogaster abdominal bristle number and other bristle systems (Clayton et al., 1957 ; LATTER \& Robertson, 1962 ; Creus, 1978 ; Marcos \& CREUS, 1981).

The variability in selection lines is shown in figure 2 . Variability did not decrease in one control line. But somewhat surprisingly it did not decrease, as might be expected, in all the selection lines. This, however, has also been found in other selection experiments and may be due to the release of new genetic variability through recombination (MATHER, 1941 ; THODAY \& BoAM, 1961 ; THODAY et al., 1964 ; Ingram \& JINKS, 1982) or due to the increase of developmental errors arising from an increased level of homozygosity (REeve \& Robertson, 1953 ; FAlCONER, 1955).

The sudden and spectacular increase in the coefficient of variation which occurred in the L2 line might be due to selection of heterozygotes for genes which are lethal in one of the homozygous combinations but which have some effect on bristle number in the heterozygous combination (Clayton et al., 1957 ; FrANKHAM et al., 1968 ; Frankham, 1970 ; Yoo, 1980). This agrees with the fact that this line (L2) is the only one that reaches a plateau while a high level of phenotypic variability still remains. Moreover, when the second set of natural selection sublines were developed the response of the L2 natural selection line supports the idea that heterozygotes for a lethal gene have increased in frequency.

MATHER (1941) observed enormous variation in abdominal bristle number, particularly in the ratio of number in the 2 sexes, among several species of Drosophila. The values of the sex-dimorphism ratio in our laboratory population and the fact that the response pattern in the selection lines was very similar between sexes within a line indicate that there is no sex-dimorphism in D. subobscura, in contrast to other species (Yoo et al., 1981). Crosses between lines show the existence of factors influencing bristle number in chromosome $\mathrm{X}$. Consequently, the lack of sex-dimorphism in this species must be due to total dosage compensation for the number of abdominal bristles.

The high degree of agreement between the response to selection in D. melanogaster and $D$. subobscura indicates that the behaviour of the genes responsible for the abdominal bristle number must be similar in the 2 species, in spite of the fact that $D$. subobscura is very rich in chromosomal polymorphisms and D. melanogaster is very poor.

Why, when selection is for wing length, does the presence of inversions provoke a stronger response than the expected (PrevostI, 1967) whereas, when selection is for abdominal bristle number, the presence of inversions seems to have no effect on response ? The answer to this question may be in the differences between the 2 traits.

A study by Prevosti (1967) gives evidence that the existence of differences in the genes controlling wing size, within the inverted regions of chromosomes, was responsible for the rapid selection response. He suggested that the selection process involves only a few units (blocks of genes) rather than individual polygenes.

For a neutral character, such as abdominal bristle number, it is reasonable that some of the chromosomal arrangements may each have some genes with a positive effect and some with a negative effect. That is to say, the different arrangements of each chromosome may have the same overall effect on the character. A similar effect 
has been found in numerous cases with enzymatic polymorphisms (Zouros et al., 1974 ; LoukAS \& Krimbas, 1980 ; CABrera et al., 1983).

If this is true, selection will tend to cause structural homozygosity (MarTinezSEBASTIAN \& DE FRUTOS, in preparation) but the response in the early generations will not be stronger than would occur if the genes influencing the trait were only partially linked. When the level of structural homozygosity increases, the suppression of recombination due to the presence of inversions will disappear (KRIMBAS \& Zouros, 1969 ; Sperlich \& Feuerbach, 1974). If recombination is then allowed, the response to selection will continue (RASmuson, 1955 ; Carson, 1958 ; MCPHEe \& RoberTson, 1970 ; MARKow, 1975) and the total response to long-term selection will be similar to the response obtained in a less polymorphic species such as $D$. melanogaster.

Received October 21, 1985.

Accepted April 18, 1986.

\section{Acknowledgements}

We would like to thank Dr. de Fruros for her valuable advice and criticism of this paper and Dr. THELEN for criticizing the paper and correcting the English text.

\section{References}

Cabrera V.M., Gonzalez A.M., Larruga J.M., Vega C., 1983. Linkage disequilibrium in chromosome A of Drosophila subobscura. Genetica, 61, 3-8.

Carson H.L., 1958. Response to selection under different conditions of recombination in Drosophila. Cold Spring Harbor Symp. Quant. Biol., 23, 219-306.

Clayton G.A., Morris J.A., Robertson A., 1957. An experimental check on quantitative genetical theory. I. Short-term response to selection. J. Genet., 55, 131-151.

Clayton G.A., Robertson A., 1957. An experimental check on quantitative genetical theory. II. The long-term effects of selection. J. Genet., 55, 152-170.

Creus A., 1978. Contribución al estudio de algunos caracteres cuantitativos de Drosophila melanogaster y de su relación con la eficacia biológica, 374 pp., Tesis Doctoral, Universidad de Barcelona.

FALCONER D.S., 1955. Patterns of response in selection experiments with mice. Cold Spring Harbor Symp. Quant. Biol., 20, 178-196.

FALCONER D.S., 1981. Introduction to Quantitative Genetics. 340 pp., Longman, London.

Frankham R., 1970. The effects of different chromosomes on four bristle number characters of Drosophila melanogaster. Aust. J. Biol. Sci., 23, 503-505.

Frankham R., Jones L.P., Barker J.S.F., 1968. The effects of population size and selection intensity in selection for a quantitative character in Drosophila. I. Short-term response to selection. Genet. Res., 12, 237-248.

INGRAM N.R., JiNKS J.L., 1982. Analysis of induced quantitative variation. II. The recombinant inbred lines. Heredity, 48, 79-84.

Kidwell J.F., Kidwell M.M., 1966. The effects of inbreeding on body weight and abdominal chaeta number in Drosophila melanogaster. Canad. J. Genet. Cytol., 8, 207-215.

Krimbas C.B., Zouros E., 1969. Crossing over suppression between linked but non overlapping inversions in D. subobscura. Dros. Inf. Serv., 44, 71-72. 
Krimbas C.B., Loukas M., 1980. The inversion polymorphism of Drosophila subobscura. Evol. Biol., 12, 163-234.

LATter B.D.H., Robertson A., 1962. The effects of inbreeding and artificial selection on reproductive fitness. Genet. Res., 3, 110-138.

Loukas M., Krimbas C.B., 1980. The genetics of Drosophila subobscura populations. XVI. Heterokaryosis and heterozygosity. Genetica, 54, 69-74.

Marcos A., CREUS R., 1981. Interocellar bristles in Drosophila melanogaster. II. Response to long-term selection. Genet. Pol., 22, 103-111.

Markow T.A., 1975. A genetic analysis of phototactic behaviour in Drosophila melanogaster. I. Selection in the presence of inversions. Genetics, 79, 527-534.

Martinez-Sebastian M.J., DE Frutos R., 1983. Chromosomal polymorphism in Drosophila subobscura populations submitted to selection for a quantitative character. Dros. Inf. Serv., 59, 79-80.

Mather K., 1941. Variation and selection of polygenic characters. J. Genet., 41, 159-193.

Mather K., Harrison B.J., 1949. The manifold effects of selection. I and II. Heredity, 3, 1-52 and 131-162.

McPhee C.P., Robertson A., 1970. The effect of suppressing crossing-over on the response to selection in Drosophila melanogaster. Genet. Res., 16, 1-6.

Prevosti A., 1967. Inversion heterozygosity and selection for wing length in Drosophila subobscura. Genet. Res., 10, 81-93.

RaSmuson M., 1955. Selection for bristle numbers in some unrelated strains of Drosophila melanogaster. Acta Zool. Stockh., 36, 1-49.

Rathie K.A., Nicholas F.W., 1980. Artificial selection with differing population structures. Genet. Res., 36, 117-132.

Reeve E.C.R., Robertson F.W., 1953. Studies in quantitative inheritance. II. Analysis of a strain of Drosophila melanogaster selected for long wings. J. Genet., 51, 276-316.

RoBertson F.W., 1960. The ecological genetics of growth in Drosophila. I. Body size and development time on different diets. Genet. Res., 1, 288-340.

Sheldon B.L., 1963. Studies in artificial selection of quantitative characters. I. Selection for abdominal bristles in Drosophila melanogaster. Aust. J. Biol. Sci., 16, 490-515.

Sperlich D., Feuerbach H., 1974. Epistatic gene interaction crossing over and linked and unlinked inversions in Drosophila subobscura. Evolution, 28, 67-75.

Thoday J.M., Boam T.B., 1961. Regular responses to selection. I. Description of responses. Genet. Res., 2, 161-176.

Thoday J.M., Gibson J.B., Spickett S.G., 1964. Regular responses to selection. II. Recombination and accelerated response. Genet. Res., 5, 1-19.

Yoo B.H., 1980. Long-term selection for a quantitative character in large replicate populations of Drosophila melanogaster. I. Response to selection. Genet. Res., 35, 1-17.

Yoo B.H., Moth J.J., BAKER J.S.F., 1981. Abdominal bristle numbers and sex-dimorphism ratios in different Drosophila species. Dros. Inf. Serv., 56, 163-164.

Zouros E., Krimbas C.B., Tsakas S., Loukas M., 1974. Genetic versus chromosomal variation in natural populations of Drosophila subobscura. Genetics, 78, 1223-1244. 